\title{
Stereotactic body radiation therapy in the treatment of ovarian cancer
}

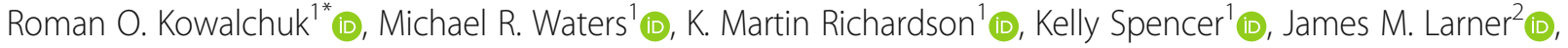 \\ William P. Irvin ${ }^{3}$ (D) and Charles R. Kersh ${ }^{1}$ (D)
}

\begin{abstract}
Background: This study evaluates the outcomes and toxicity of stereotactic body radiation therapy (SBRT) in ovarian cancer.

Methods: This retrospective analysis considered all patients treated with SBRT from 2009 to 2018 with a primary ovarian tumor. Follow-up included PET-CT and CT scans at 2-3 month intervals. Statistical analysis primarily consisted of univariate analysis, Cox proportional hazards analysis, and the Kaplan-Meier method.

Results: The study included 35 patients with 98 treatments for lymph nodes (51), local recurrence (21), and de novo solid metastases (26). Median biologically effective dose (BED), gross tumor volume, and planning target volume were $38.40 \mathrm{~Gy}, 10.41 \mathrm{cc}$, and $25.21 \mathrm{cc}$, respectively. 52 lesions showed complete radiographic response, and two-year local control was $80 \%$. Median overall survival (OS) was 35.2 months, and two-year progression-free survival (PFS) was 12\%. On univariate analysis, Eastern Cooperative Oncology Group performance status $>0$ was predictive of decreased OS $(p=0.0024)$ and PFS $(p=0.044)$. Factors predictive of local failure included lower BED $(p=0.016)$, treatment for recurrence $(p=0.029)$, and higher pre-treatment SUV $(p=0.026)$. Kaplan-Meier analysis showed BED $\leq 35$ Gy $(p<0.005)$ and treatment for recurrence $(p=0.01)$ to be predictive of local failure. On Cox proportional hazards analysis, treatment of lymph nodes was predictive of complete radiographic response (hazard ratio $(H R)=4.95)$, as was higher $B E D(H R=1.03)$. Toxicity included 27 cases of grade $<3$ toxicity, and one grade 5 late toxicity of $\mathrm{Gl}$ bleed from a radiation therapy-induced duodenal ulcer.
\end{abstract}

Conclusions: SBRT provides durable local control with minimal toxicity in ovarian cancer, especially with BED $>35$ Gy and treatment for lymph nodes.

Keywords: SBRT, SABR, Ovarian cancer, Radiation oncology

\section{Introduction}

Ovarian cancer is a heterogeneous disease without clear screening guidelines for early detection [1-5]. It is often diagnosed at advanced stages of disease, resulting in relapse in $75 \%$ of patients and the frequent need for salvage therapy [6-9]. The biology of relapse may involve treatment resistance stemming from a sub-population of

\footnotetext{
*Correspondence: Roman.Kowalchuk@rivhs.com; okowal17@gmail.com 'University of Virginia / Riverside, Radiosurgery Center, Newport News, VA, USA

Full list of author information is available at the end of the article
}

cancer stem cells or changes within the tumor microenvironment and extracellular matrix [8-11]. Advances in molecularly targeted treatments, however, have helped extend patient survival [12-14].

A variety of radiation techniques are currently being considered in the management of ovarian cancer, including intensity-modulated radiotherapy, stereotactic body radiotherapy (SBRT), and low-dose hyperfractionation combined with targeted agents $[15,16]$. Postoperative pelvic radiotherapy and radiotherapy after chemotherapy in advanced disease have also emerged as possible uses

(c) The Author(s). 2020 Open Access This article is licensed under a Creative Commons Attribution 4.0 International License, which permits use, sharing, adaptation, distribution and reproduction in any medium or format, as long as you give appropriate credit to the original author(s) and the source, provide a link to the Creative Commons licence, and indicate if changes were made. The images or other third party material in this article are included in the article's Creative Commons licence, unless indicated otherwise in a credit line to the material. If material is not included in the article's Creative Commons licence and your intended use is not permitted by statutory regulation or exceeds the permitted use, you will need to obtain permission directly from the copyright holder. To view a copy of this licence, visit http://creativecommons.org/licenses/by/4.0/. The Creative Commons Public Domain Dedication waiver (http://creativecommons.org/publicdomain/zero/1.0/) applies to the data made available in this article, unless otherwise stated in a credit line to the data. 
for radiotherapy [17]. In one study, involved-field radiation therapy for locoregionally-recurrent ovarian cancer demonstrated an impressive 5 year in-field disease control rate of $71 \%$, and another analysis showed a $65 \%$ response rate to radiation therapy for recurrent epithelial ovarian cancer $[18,19]$. Unfortunately, stringent guidelines regarding the use of radiotherapy in ovarian cancer do not exist. Therefore, available studies investigating the use of radiation in ovarian cancer include a range of radiotherapy techniques and a mix of ovarian cancer subtypes [20-22].

SBRT, also known as stereotactic ablative radiotherapy (SABR), is a radiation therapy strategy that involves delivering high doses of radiation to the tumor in relatively few treatments (about 3-6) [23]. SBRT has shown efficacy in the treatment of oligometastases from colorectal cancer, especially when the target of treatment has been a lymph node or small tumor [24, 25]. Further studies have included other primary solid tumors, including the lung and prostate. SBRT may be most efficacious in carefully selected patients with a disease-free interval of $\geq 12$ months, control of the primary tumor, small lesions, a limited number of lesions, and a higher delivered radiation dose [26-30]. The SABR-COMET trial, a randomized phase 2 study, demonstrated that SABR in patients with a limited number of metastatic lesions resulted in improved overall survival [31].

The role of SBRT in metastatic gynecologic cancer has also been studied and found to be safe and efficacious, particularly when targeting lymph node recurrences [32, 33]. The largest analysis considering SBRT for ovarian cancer metastases was a multi-institutional study that reported completed response in $65.2 \%$ of treatments. Lymph node disease was correlated with complete response, but further single institutional study is needed [34-37]. This study aims to analyze the outcomes and toxicity of SBRT in ovarian cancer at a single highvolume stereotactic radiosurgery center and discern factors predictive of overall survival (OS), local control, and radiographic response.

\section{Methods}

This retrospective analysis considered all patients at a single institution treated with SBRT for a primary ovarian tumor from April 2009-November 2018. An intention-to-treat model was undertaken, so each patient treated was included in the analysis. No exclusion criteria were specified, so patients were included regardless of the SBRT target (lymph node, recurrence, or de novo solid metastasis). Treatment for recurrence was further delineated into local, regional, and distant recurrence. Local recurrence was defined as a previously treated lesion that had grown in size on imaging. Previous treatment may have included surgical resection, chemotherapy, and radiation therapy. New lesions arising within the planning target volume (PTV) of previous radiotherapy were also included as local recurrences. Regional recurrence was denoted as new disease in proximity to a previous lesion and without an anatomic barrier separating the lesions. For instance, a new abdominal lesion in the setting of prior abdominal disease would be deemed a regional recurrence. Other disease progression not meeting these criteria was denoted as distant recurrence. Patients of all pathological subtypes were included, and the corresponding histology was recorded.

The number of treated lesions and the performance status were recorded for each patient, and no restrictions were made regarding the maximum lesion size for inclusion in the study. The authors decided that since no explicit exclusion criteria regarding lesion size have been developed in the setting of ovarian cancer, all patients treated with SBRT for ovarian cancer should be included. Pre- and post-chemotherapy CA125 levels were noted, as was each patient's response to chemotherapy. Prior and subsequent treatments were also included, as were each patient's platelet, lymphocyte, and neutrophil counts prior to and after treatments (when available). Follow-up included PET-CT and CT imaging at 2-3 month intervals, and standardized uptake values (SUV) and CA125 lab values were recorded prior to and after treatment. PET-CT generally involved total body scans using ${ }^{18} \mathrm{FDG}$, and the target of the CT scan varied, depending on the location of the SBRT target. Most frequently, CT abdomen/pelvis was used. Key dosimetric data included the dose, fractions, days between fractions, and the dose-fractionation scheme of any prior radiation. An alpha/beta ratio of $10 \mathrm{~Gy}$ was used for calculations of the biologically effective dose (BED), using the formula $\mathrm{BED}=$ total dose * $(1+$ dose per fraction / alpha/beta ratio). The study was exempt by the institutional review board.

Patients were immobilized prior to planning the CT scan using a full-body vacuum bag system for position stabilization and consistency. Dose was prescribed to the PTV, which was defined as the gross tumor volume (GTV) plus 3-5 mm of margin to account for uncertainties in imaging and localization. In general, a threedimensional conformal treatment planning approach was used with non-coplanar gantry angles to minimize dosimetric overlap of entrance and exit portals. Intensity-modulated radiotherapy and volumetricmodulated arc therapy were considered, but they were not used in this setting. Treatments were instead completed with multiple non-coplanar static gantry delivery. SBRT was delivered using a $6 \mathrm{MV}$ photon beam on a linear accelerator with a $2.5 \mathrm{~mm}-4 \mathrm{~mm}$ width multi-leaf collimator for custom shaping of portals. An on-board cone-beam $\mathrm{CT}$ was used prior to treatment to align the 
patient. It was also used several times (generally 2-4) during treatment to correct for intra-fraction movement. A robotic couch with six degrees of freedom assisted in the alignment of the patient and localization of the target to the planning CT. Treatments were generally delivered once weekly. The median days between fractions was reported in a non-inclusive manner, such that there were 6 days between once-weekly treatments.

The key endpoints of the analysis involved overall survival (OS), local control, and radiographic response. Progression-free survival (PFS) and time to salvage were secondary endpoints. Two-year local control and twoyear PFS were determined using the Kaplan-Meier method. Patient follow-up was generally conducted by radiation oncology, hematology-oncology, or gynecologiconcology. Imaging was used to classify treatment response as progressive, stable, partial, or complete. Any treatment failure was also noted on imaging, and it was distinguished as local, regional, or distant failure. Acute and chronic toxicity findings were tabulated according to the Common Terminology Criteria for Adverse Events v5.0. Ninety days was the cutoff for delineating acute from chronic toxicity.

Statistical analysis was conducted for each treated lesion to analyze local control and radiographic response, and survival analysis was performed for each patient treated. Predictive factors for overall survival and local control were assessed via Cox proportional hazards regression analysis and univariate analysis, with an alpha value of 0.05 . Local control and overall survival were further described using the Kaplan-Meier method, including distinctions between the overall survival and local control of different subgroups of the cohort.

\section{Results}

Thirty-five patients with ninety-eight treated lesions were included. Seventeen patients were treated for one lesion, but eighteen patients were treated for at least two distinct lesions with SBRT, including seven patients receiving at least 5 treatments. Of patients with multiple treatments, five patients had only synchronous lesions, seven had only metachronous lesions, and six suffered from both synchronous and metachronous lesions. The time of presentation for SBRT was a median 44.81 months after primary diagnosis. Only two patients presented for SBRT within 12 months of primary diagnosis. Twenty-one (60\%) patients had Eastern Cooperative Oncology Group (ECOG) performance status 0 at the time of consultation for SBRT. Five patients (14\%) had a diagnosed BRCA1 mutation, and $2(6 \%)$ were positive for homologous recombination deficiency. The majority of patients (66\%) had a serous papillary adenocarcinoma on pathologic review, and the other subtypes included clear cell, transitional cell, granulosa cell, endometrioid, carcinosarcoma, mucinous, and other poorly differentiated tumors (Table 1).

Pre-SBRT chemotherapy and further tumor details were also reported for each patient. At diagnosis, most

Table 1 Patient demographics are carefully explored

\begin{tabular}{|c|c|c|}
\hline Patient Demographics & Number & Rate \\
\hline Total patients & 35 & \\
\hline Total lesions & 98 & \\
\hline Patients with 1 lesion & 17 & $49 \%$ \\
\hline Patients with 2 lesions & 6 & $17 \%$ \\
\hline Patients with 3 lesions & 2 & $6 \%$ \\
\hline Patients with 4 lesions & 3 & $9 \%$ \\
\hline Patients with $\geq 5$ lesions & 7 & $20 \%$ \\
\hline Median age at diagnosis (years) & $62.8(32.7-80.6)$ & \\
\hline ECOG 0 & 21 & $60 \%$ \\
\hline ECOG 1 & 11 & $31 \%$ \\
\hline ECOG 2 & 1 & $3 \%$ \\
\hline ECOG 3 & 2 & $6 \%$ \\
\hline ECOG 4 & 0 & $0 \%$ \\
\hline \multicolumn{3}{|l|}{ Histology } \\
\hline Serous papillary adenocarcinoma & 23 & $66 \%$ \\
\hline Mixed & 1 & $3 \%$ \\
\hline Clear cell & 1 & $3 \%$ \\
\hline Transitional cell & 1 & $3 \%$ \\
\hline Granulosa cell & 1 & $3 \%$ \\
\hline Endometrioid & 2 & $6 \%$ \\
\hline Carcinosarcoma (mixed Mullerian) & 2 & $6 \%$ \\
\hline Poorly differentiated / Undifferentiated & 3 & $9 \%$ \\
\hline Mucinous & 1 & $3 \%$ \\
\hline Positive BRCA 1 & 5 & $14 \%$ \\
\hline Positive HRD & 2 & $6 \%$ \\
\hline Neoadjuvant chemotherapy & 8 & $23 \%$ \\
\hline No neoadjuvant chemotherapy & 27 & $77 \%$ \\
\hline Gross residual post-op & 14 & $40 \%$ \\
\hline No gross residual post-op & 21 & $60 \%$ \\
\hline Median post-chemotherapy CA125 & 18 & \\
\hline Median pre-SBRT SUV & 5.5 & \\
\hline \multicolumn{3}{|l|}{ Staging at Diagnosis } \\
\hline Stage I & 5 & $14 \%$ \\
\hline Stage ॥ & 3 & $9 \%$ \\
\hline Stage III & 18 & $51 \%$ \\
\hline Stage IV & 9 & $26 \%$ \\
\hline Grade 1 & 1 & $3 \%$ \\
\hline Grade 2 & 4 & $11 \%$ \\
\hline Grade 3 & 26 & $74 \%$ \\
\hline Grade NA & 4 & $11 \%$ \\
\hline
\end{tabular}


patients presented at advanced stages of disease (51\% at stage 3 and $26 \%$ at stage 4 ). Of these, twenty-two treated lesions initially presented with nodal spread, and only ten presented with $\mathrm{T}$ stage less than 3 . Most tumors were grade 3 on pathologic review (74\%), and only one case involved a well-differentiated, grade 1 tumor. Surgical interventions were varied. They included a range of primary goals: exploration (11\%), debulking (34\%), lymph node resection or sampling (14\%), omentectomy (31\%), peritoneal stripping (11\%), and bowel resection (37\%). Some form of total abdominal hysterectomy with or without unilateral or bilateral oophorectomy was also undertaken in $49 \%$ of cases. Many patients (40\%) still had gross residual disease after the initial debulking surgery, but $78.4 \%$ of patients were sensitive to chemotherapy. All but one chemotherapy regimen included carboplatin. The treatments included carboplatin and paclitaxel (83\%), carboplatin alone (6\%), carboplatin and docetaxel (9\%), carboplatin and gemcitabine (3\%), cisplatin and paclitaxel (3\%), and carboplatin, gemcitabine, and bevacizumab (3\%). Four patients used two primary chemotherapy regimens, and the median number of cycles of chemotherapy was six. CA125 was reduced after chemotherapy in the majority of cases. Six patients (17\%) had received radiotherapy prior to SBRT. Five of these treatments were related to ovarian cancer, including whole pelvis radiotherapy, radiotherapy for bone metastases, and brachytherapy.

The median dose and fractionation were $24 \mathrm{~Gy}$ in 4 fractions, with a median 4 days between fractions. The most common dose-fractionation schemes were $20-24$ Gy in 3-4 fractions (55\%), 30-40 Gy in 3-5 fractions (26\%), and 15-18 Gy in 3-4 fractions (14\%). Median BED was 38.40 Gy, and median GTV and PTV were 10.41 and $25.21 \mathrm{cc}$, respectively. There was no limit imposed on the maximum GTV for inclusion in the study, so large tumors were also included (maximum GTV of $272.37 \mathrm{cc}$ ). Even so, lesions were generally smaller. Only seven treatments involved a GTV $>50 \mathrm{cc}$. Concurrent chemotherapy was involved in only six cases. Treatments were for lymph nodes (51), local recurrence (21), and de novo solid metastases (26). Treatments for local recurrence generally involved abdominal soft tissue (62\%) or perigastric (19\%) targets after surgical intervention and chemotherapy. In six instances, local recurrence involved re-treatment with SBRT, and in fifteen cases, radiotherapy followed treatment failure of surgery or chemotherapy. Of patients treated for de novo metastases, $77 \%$ of treatments targeted liver metastases, with the spleen, lung, and bone comprising the other treated locations (Table 2). Though there were no differences in GTV or PTV between treatments for recurrence and de novo solid metastases, treatments for recurrence had increased GTV $(p=0.03)$ and PTV $(p=0.003)$ relative to treatments for lymph nodes.
Table $\mathbf{2}$ The details of the radiation therapy are tabulated

\begin{tabular}{lll}
\hline Dosimetric Characteristics & Number & Rate \\
\hline Median dose (Gy) & $24(12-40)$ & \\
Median fractions & $4(3-6)$ & \\
Median BED (Gy) & $38.40(16.80-84.38)$ & \\
Median GTV (cc) & $10.41(0.30-272.37)$ & \\
Median PTV (cc) & $25.21(1.79-393.07)$ & \\
Mean days between fractions & 5.39 & $6 \%$ \\
Concurrent chemotherapy & 6 & \\
SBRT Target & & $77 \%$ \\
Extrapelvic & 75 & $23 \%$ \\
Intrapelvic & 23 & $21 \%$ \\
Local recurrence & 21 & $52 \%$ \\
Lymph node & 51 & $2 \%$ \\
Spleen & 2 & $20 \%$ \\
Liver & 20 & $2 \%$ \\
Lung & 2 & $2 \%$ \\
Bone & 2 & \\
\hline
\end{tabular}

Median follow-up was 33.67 months. Median OS was 35.2 months, and two-year PFS was $12 \%$. OS at 2 years was $60 \%$. On imaging follow-up, 52 lesions (53\%) showed complete radiographic response, and partial response, lesion stability, and tumor progression were reported in 21,12 , and $1 \%$ of cases, respectively. Lesion size decreased a median $29.2 \%$ after SBRT on the first imaging follow-up. Local control was maintained in 81 cases, resulting in a two-year local control rate of $80 \%$ (Table 3). These results were demonstrated using the Kaplan-Meier method (Fig. 1). Failure patterns included distant (39\%), regional (32\%) and local (17\%) relapse. Subsequent treatments included salvage chemotherapy $(63 \%)$, radiotherapy $(36 \%)$, and surgery $(6 \%)$. The median time to salvage therapy was 4.29 months. Neutrophil, platelet, and lymphocyte counts were also recorded prior to and after SBRT. These counts decreased by a median $10.53,8.57$, and $14.29 \%$.

Univariate analyses were conducted, in addition to Cox proportional hazards regression analysis. ECOG $>0$ was the only factor predictive of decreased OS $(p=$ $0.0024)$ and PFS $(p=0.044)$. On the other hand, factors predictive of local failure on univariate analysis included lower $\operatorname{BED}(p=0.016)$, treatment for recurrence $(p=$ $0.029)$, and higher pre-treatment SUV $(p=0.026)$. Treatment of liver metastases was also predictive of local control $(p=0.025)$. On Cox proportional hazards analysis, larger GTV volume was predictive of local failure (hazard ratio $(\mathrm{HR})=1.04$ ), but the prognostic impact of the treatment target led to wide confidence intervals (Table 4). On Kaplan-Meier analysis, BED $\leq 35$ Gy was predictive of local failure $(p<0.005)$, as was treatment 
Table 3 Patient outcomes, including imaging response, disease relapse, and survival are considered

\begin{tabular}{lll}
\hline Outcome & Number & Rate \\
\hline No relapse & 18 & $18 \%$ \\
Relapse & 80 & $82 \%$ \\
Two-year local control & & $80 \%$ \\
Local relapse & 17 & $17 \%$ \\
Regional relapse & 31 & $32 \%$ \\
Distant relapse & 38 & $39 \%$ \\
Salvage chemotherapy & 62 & $63 \%$ \\
Salvage radiotherapy & 35 & $36 \%$ \\
Salvage surgery & 6 & $6 \%$ \\
No salvage treatment & 9 & $9 \%$ \\
Median time to salvage (months) & $4.29(0.26-51.98)$ & \\
Alive & 18 & $51 \%$ \\
Deceased & 17 & $12 \%$ \\
Median overall survival (months) & $35.19(1.81-97.64)$ & \\
Two-year PFS & & $12 \%$ \\
Imaging Response & & \\
$\quad$ Progressive & $12 \%$ \\
$\quad$ Stable & $12 \%$ \\
$\quad$ Partial & $12.13(0.40-15.10)$ & \\
$\quad$ Complete & 29.17 & \\
$\quad$ No imaging follow-up & $10.53 \%$ & \\
Target size after SBRT (cm) & $52.37 \%$ & \\
Reduction in target size (\%) & & \\
Median neutrophil count reduction & & \\
Median platelet count reduction & & \\
Median lymphocyte count reduction & $14.29 \%$ & \\
\hline
\end{tabular}

for recurrence $(p=0.01)$ (Figs. 2 and 3). Kaplan-Meier analysis failed to demonstrate any difference in local control rates between patients with longer versus shorter times to treatment or any of the other factors previously discussed.

Factors predictive of incomplete radiographic response included treatment for recurrence $(p=0.0030)$ and higher pre-treatment SUV $(p=0.035)$. Additionally, target size trended towards significance $(p=0.071)$. On Cox proportional hazards analysis, treatment of lymph nodes was predictive of complete radiographic response (HR = 4.95), as was higher BED ( $\mathrm{HR}=1.03)$ (Fig. 4). In the hazards analysis, SBRT for a liver metastasis target was used as a surrogate for SBRT for metastasis because the analysis using SBRT for metastases in this context demonstrated high collinearity, and 20 of 26 cases $(77 \%)$ of treatment for metastasis involved treatment of a liver mass. Additionally, pre-treatment SUV was not included in the hazards analysis because not all patients had a pre-treatment PET scan. No differences in outcomes were seen depending on the changes in neutrophil, platelet, or lymphocyte counts.

Toxicity included 22 cases of acute grade 1 toxicity, five instances of acute grade 2 toxicity, and one late grade 5 late toxicity of GI bleed from what was believed to be a radiation therapy-induced duodenal ulcer. This case involved the delivery of $18 \mathrm{~Gy}$ in three fractions to a $1.93 \mathrm{~cm}$ target in the porta hepatis of the liver. The patient had received a separate SBRT treatment one month prior to a distinct porta hepatis lesion. This lesion had been treated with $21 \mathrm{~Gy}$ in three fractions to a PTV of $58.24 \mathrm{cc}$. The most common acute grade 1 toxicities were seven instances of nausea and vomiting and seven of fatigue. Other acute grade 1 side effects included pain (4 cases), erythema (2 cases), and diarrhea (2 cases). Acute grade 2 toxicity involved nausea and vomiting (three cases) and pain (two cases) (Appendix).

\section{Discussion}

Local failure was one of the principal endpoints of this study, and the results were encouraging, with $83 \%$ local control at a median follow-up time of 33.67 months. This follow-up time is quite extensive, as many studies regarding SBRT for ovarian cancer include only 12-24 months of follow-up. The largest study to date of SBRT in oligometastatic ovarian cancer was written by Macchia, et al., a multi-institutional study of 15 centers considering 446 lesions treated in 261 patients, and the results were quite similar to those presented here. At a median follow-up of 22 months, the 24-month actuarial local control rate was $81.9 \%$. Local control was associated with complete radiographic response and total dose $>25$ Gy [34]. Iftode et al. reported a local control rate of $92.9 \%$ at 1 year, and Trippa et al. found a local control of $73 \%$ in a subset of lymph node disease secondary to ovarian cancer treated with SBRT [35, 36]. Trippa et al. also determined that higher dose was correlated with improved local control. Finally, Lazzari et al. presented the largest single-institutional study to date involving SBRT in oligometastatic ovarian cancer, but they only reported a complete radiographic response in $60 \%$ at 17.4 months of follow-up [34]. Overall, the local control rate from this study is consistent with the literature in that SBRT offers treatment efficacy in metastatic ovarian cancer. Nonetheless, there are very few studies evaluating the outcomes of SBRT in this context. For this reason, it is unsurprising that there is heterogeneity between the inclusion and exclusion criteria in the studies discussed above. Trippa et al. only presented data regarding the treatment of lymph node disease, and the evaluation of a study considering results from 15 institutions is also complicated by the differences in treatment 

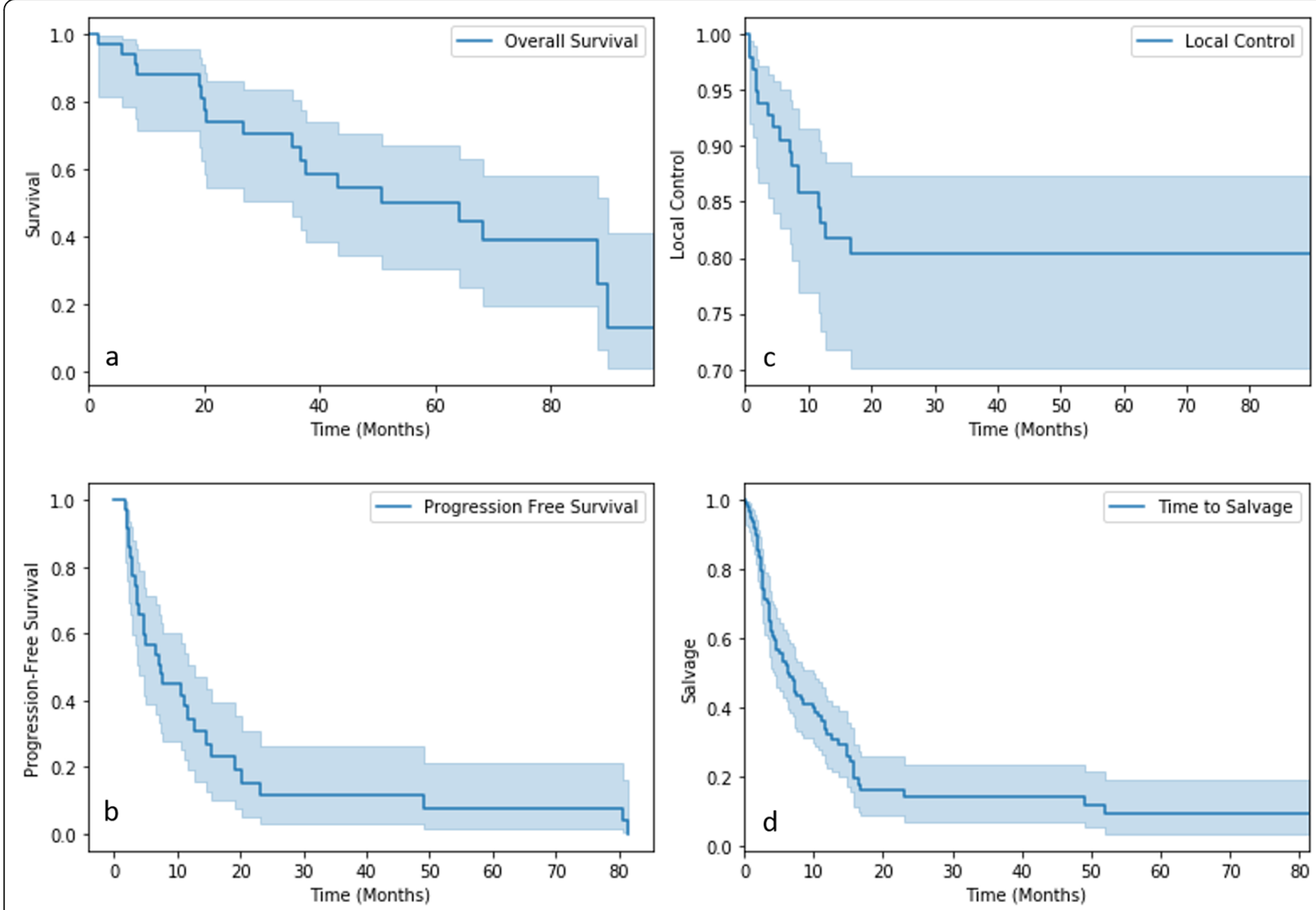

Fig. 1 Kaplan-Meier curves of OS, PFS, local control, and time to salvage are shown

planning between those centers [34, 37]. Other papers have considered metastases from a variety of primary gynecologic cancers [36].

In this analysis, factors predictive of local failure included BED $\leq 35 \mathrm{~Gy}$, larger GTV, treatment for recurrence, and higher pre-treatment SUV. Treatment of liver metastases was also predictive of local control.
Unfortunately, it is difficult to directly compare these results to literature values because the few studies concerning this topic have either not included sufficient numbers of treatments for such analyses or have focused on a different endpoint. Radiographic response has been used as a surrogate for local control, and it was the chief endpoint presented by Lazzari et al. Macchia et al. found

Table 4 The results of the univariate and Cox proportional hazards analyses are shown. Bolded $p$ values indicate statistical significance

\begin{tabular}{llll}
\hline \multirow{2}{*}{ Predictive factor } & Local failure & & $\begin{array}{l}\text { Complete radiographic response } \\
\text { Univariate analysis }(p \text { value) }\end{array}$ \\
\cline { 2 - 3 } BED $($ Gy $)$ & $\mathbf{0 . 0 1 6}$ & $0.95(0.91-1.00)$ & 0.52 \\
- BED $\leq 35$ & $\mathbf{0 . 0 1 7}$ & & 0.087 \\
GTV & 0.22 & $1.04(1.00-1.08)$ & 0.19 \\
PTV & 0.62 & $0.98(0.95-1.01)$ & 0.49 \\
Target size & 0.16 & $1.04(0.82-1.31)$ & 0.071 \\
Treatment for recurrence & $\mathbf{0 . 0 2 9}$ & $0.71(0.07-7.79)$ & $\mathbf{0 . 0 0 3}$ \\
Treatment for lymph node & 0.34 & $0.36(0.04-3.32)$ & $\mathbf{0 . 0 2 7}$ \\
Treatment for liver metastasis & $\mathbf{0 . 0 2 5}$ & $0.20(0.01-3.65)$ & 0.79 \\
Time from primary diagnosis & 0.20 & $1.00(0.99-1.02)$ & 0.49 \\
Higher pre-treatment SUV & $\mathbf{0 . 0 2 6}$ & & $\mathbf{0 . 0 3 5}$ \\
\hline
\end{tabular}




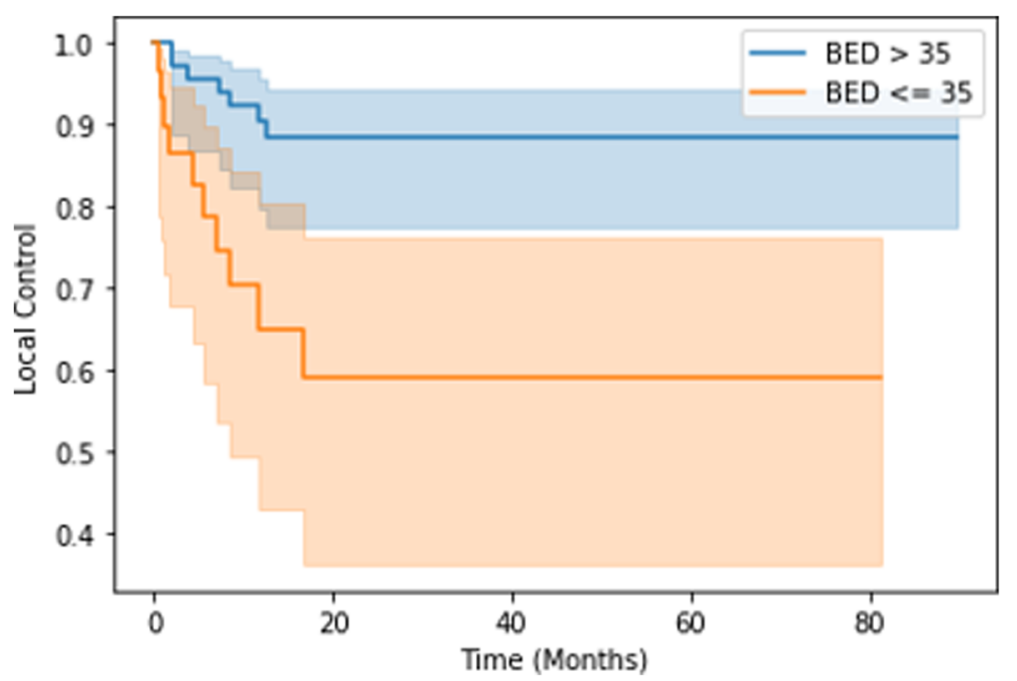

Fig. 2 Kaplan-Meier analysis demonstrates improved local control with BED > 35 Gy $(p<0.005)$

that age $\leq 60$ years, PTV $\leq 18 \mathrm{cc}$, lymph node disease, and BED $>70$ Gy were associated with complete radiographic response. These factors were not found to be directly correlated with local control. In this analysis, complete response was observed in 52 cases, which is $53 \%$ of all cases included in the study but $60 \%$ of all cases with follow-up imaging. This result is quite consistent with literature values of $61.8-65.2 \%[34,35]$. Here, factors predictive of incomplete radiographic response included treatment for recurrence and higher pre-treatment SUV. The increased local failure with higher pre-treatment SUV points towards a potential prognostic role for PET imaging. Lung lesion shrinkage of at least $20 \%$ at the last session of SABR on cone-beam CT has been investigated as a predictive factor of complete response [38]. Additionally, the maximum and mean SUV values on
${ }^{18}$ FDG-PET/CT have also been shown to be predictive of complete response [39]. These findings point towards the need for further investigation of pre-treatment SUV as a prognostic factor.

The concept of higher dose delivery resulting in improved local control and even improved survival rates has been observed with SBRT in other solid malignancies $[31,37,40]$. For instances, high rates of treatment efficacy have been observed for liver metastases with BED > 100 Gy [41]. Smaller tumor size or treatment volume intuitively may relate to improved treatment efficacy for a variety of reasons [25,37]. For instance, higher dose may be more feasibly delivered to this location while minimizing toxicity. Finally, the result that SBRT is more effective for lymph node disease and less efficacious when treatment is for cancer recurrence is

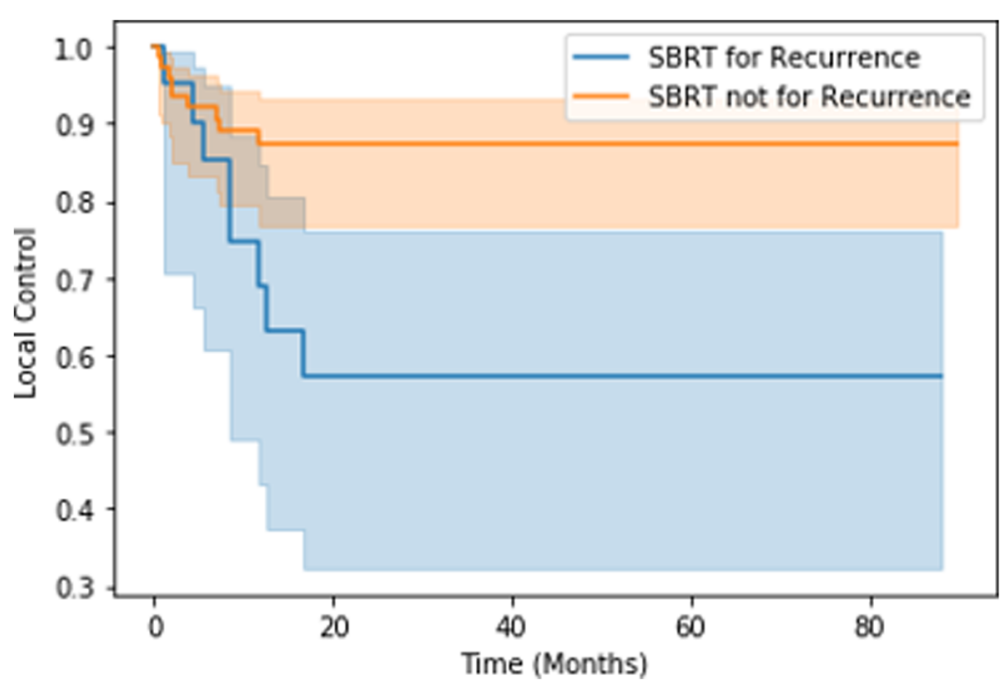

Fig. 3 Kaplan-Meier analysis shows decreased local control with SBRT for recurrence $(p=0.01)$ 


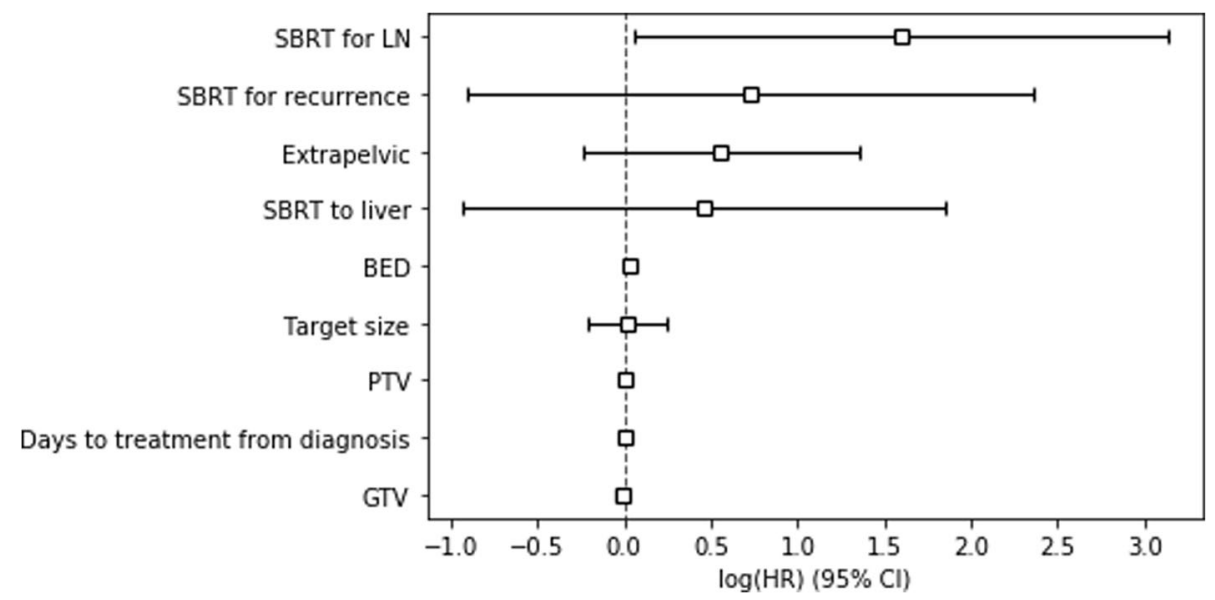

Fig. 4 Cox proportional hazards analysis for predictive factors of complete radiographic response is displayed

intriguing. Results for SBRT treatment of lymph node disease from a variety of primary cancers have been encouraging, so it is not surprising that results in this patient subgroup were positive [24, 28, 33]. Salvage treatments have been somewhat more complex, as they present a different set of challenges. These include difficulties with delivering high dose radiation again within a prior radiation treatment field and concerns about the radioresistance of the tumor. This patient subgroup of ovarian cancer patients who need treatment of recurrent disease requires further study because their outcomes may be worse than those receiving primary treatment with SBRT, and relapse rates within 2 years of primary therapy are about $75 \%$ [7]. One potential contributing factor to this difference could be the treatment volume because treatments for recurrence had increased GTV and PTV relative to treatments for lymph nodes. Even so, treatment for recurrence was independently predictive of local failure on Kaplan-Meier analysis, and treatment for lymph nodes predicted for complete radiographic response. Volume did not have a statistically significant impact on complete radiographic response or local control via the Kaplan-Meier method, so it is possible that the treatment target is the dominant factor. Further study into this distinction is recommended.

Survival in this patient cohort was quite impressive, with a median overall survival of 35.2 months. This value is much higher than the poor survival generally presented in the literature [3,9]. ECOG $>0$ was the only factor predictive of decreased OS $(p=0.0024)$ and PFS $(p=0.044)$. It is possible that the patients in this study had relatively high performance statuses compared with other ovarian cancer patients, as $60 \%$ of patients had ECOG 0 and 31\% had ECOG 1. On the other hand, the majority of patients in this study (51\%) were treated with SBRT for multiple lesions. This was in the context of a progression-free survival of 7.2 months and median time to salvage of 4.29 months. Lazzari et al. noted a similar treatment-free interval after SBRT of 7.4 months [35]. Large database study will likely play a key role in further studying overall survival [42]. The development of a nomogram assessing the role of pretreatment characteristics indicated that performance status, ascites, size of the largest tumor, CA125, platinum-free interval, and primary platinum resistance were the significant predictors for OS [43]. Further study of these factors may help optimize patient selection of ovarian cancer patients for SBRT.

Toxicity in this study was quite low overall, with 22 cases of grade 1 toxicity, five instances of grade 2 toxicity, and one grade 5 late toxicity of GI bleed from what was believed to be a radiation therapy-induced duodenal ulcer. The most common side effects of nausea, vomiting, and fatigue were not severe. These were also relatively non-specific symptoms that may have been related to the primary disease process. There was only 1 case of grade $\geq 3$ toxicity, which involved the grade 5 GI bleed. Similarly, Macchia et al. reported that only $20.7 \%$ of patients suffered from any toxicity, none of which was grade $\geq 3$ [34]. Lazzari et al. also noted no grade $\geq 3$ toxicity for SBRT in oligometastatic ovarian cancer [35]. These findings together point towards the safety of this technique.

This study suffers from some limitations regarding the inclusion of only 35 distinct patients. This could serve to depress the ability of the authors to determine prognostic factors regarding survival and could lead to high variance in the survival outcomes. Additionally, the inclusion of treatments involving local relapse may represent a significance weakness of the present analysis. It was shown that treatments for recurrence had increased rates of local failure, and they may represent a distinct clinical question from treatments for lymph nodes or de novo solid metastases. Further study is recommended to 
clarify this distinction, as well as the role of systemic treatment in this setting. Relatively low prescription doses were used in this study. It is possible that higher doses might have improved the complete response rate, and further study into the use of higher doses is recommended.

\section{Conclusions}

The authors were able to analyze a large cohort of lesions treated with SBRT from primary ovarian cancer at a single institution and present the findings that the technique was associated with high rates of local control, impressive survival, and minimal toxicity. Patients with $\mathrm{BED} \leq 35 \mathrm{~Gy}$, larger GTV, and treatment for recurrence had increased local failure while those with treatments for lymph node disease had improved local control.

\section{Appendix}

Table $\mathbf{5}$ Toxicity results are demonstrated

\begin{tabular}{lllll}
\hline Acute & Grade 1 & Grade 2 & Grade 3-4 & Grade 5 \\
\hline NauseaNomiting & 7 & 3 & 0 & 0 \\
Fatigue & 7 & 0 & 0 & 0 \\
Pain & 4 & 2 & 0 & 0 \\
Erythema & 2 & 0 & 0 & 0 \\
Diarrhea & 2 & 0 & 0 & 0 \\
Total & 22 & 5 & 0 & 0 \\
Late & & & & \\
$\quad$ Duodenal ulcer & 0 & 0 & 0 & 1 \\
$\quad$ Total & 0 & 0 & 0 & 1 \\
\hline
\end{tabular}

\section{Abbreviations}

SBRT: Stereotactic body radiation therapy; PET: Positron emission tomography; CT: Computed tomography; BED: Biologically effective dose; GTV: Gross tumor volume; PTV: Planning target volume; OS: Overall survival; PFS: Progression-free survival; SUV: Standardized uptake values; CA125: Cancer antigen 125; SABR: Stereotactic ablative radiotherapy; ECOG: Eastern Cooperative Oncology Group

\section{Acknowledgements}

None.

\section{Authors' contributions}

ROK and CRK were chiefly involved in project conceptualization. ROK primarily collected and analyzed the data. MRW served as the primary editor of the initial draft of the manuscript. KMR and KS contributed to the project methodology. JML and WPI provided edits and clinical recommendations throughout the project. WPI and CRK oversaw most of the project and served as key mentors. All authors read and approved the final manuscript.

\section{Funding}

Not applicable.

\section{Availability of data and materials}

The datasets generated during and/or analyzed during the current study are available from the corresponding author on reasonable request.
Ethics approval and consent to participate

An exemption was granted by the institutional review board, and the research was conducted in accordance with their tenets.

\section{Consent for publication}

Not applicable.

\section{Competing interests}

The wife of Dr. Kowalchuk is a senior technical product manager at GE Healthcare. No other authors have any conflicts or interests, competing interests, or disclosures.

\section{Author details}

${ }^{1}$ University of Virginia / Riverside, Radiosurgery Center, Newport News, VA, USA. ${ }^{2}$ Department of Radiation Oncology, University of Virginia, Charlottesville, VA, USA. ${ }^{3}$ Department of Gynecologic Oncology, Riverside Regional Medical Center, Newport News, USA.

Received: 3 March 2020 Accepted: 6 May 2020

Published online: 13 May 2020

\section{References}

1. Reid BM, Permuth JB, Sellers TA. Epidemiology of ovarian cancer: a review. Cancer Biol Med. 2017;14(1):9. https://doi.org/10.20892/j.issn. 2095-3941.2016.0084.

2. Bast RC, Hennessy B, Mills GB. The biology of ovarian cancer: new opportunities for translation. Nat Rev Cancer. 2009;9(6):415-28. https://doi. org/10.1038/nrc2644.

3. Cho KR, Shih IM. Ovarian cancer. Ann Rev Pathol: Mechan Dis. 2009;4:287313. https://doi.org/10.1146/annurev.pathol.4.110807.092246.

4. Doubeni CA, Doubeni AR, Myers AE. Diagnosis and management of ovarian cancer. Am Fam Physician. 2016;93(11):937-44.

5. Roett MA, Evans P. Ovarian cancer: an overview. Am Fam Physician. 2009; 80(6):609-16.

6. Vargas-Hernández VM, Moreno-Eutimio MA, Acosta-Altamirano G, VargasAguilar VM. Management of recurrent epithelial ovarian cancer. Gland Surg. 2014;3(3):198. https://doi.org/10.3978/j.issn.2227-684X.2013.10.01.

7. Tummala MK, McGuire WP. Recurrent ovarian cancer. Clin Adv Hematol Oncol. 2005;3(9):723-36.

8. Ushijima K. Treatment for recurrent ovarian cancer-at first relapse. J Oncol. 2010:2010. https://doi.org/10.1155/2010/497429.

9. Bhoola S, Hoskins WJ. Diagnosis and management of epithelial ovarian cancer. Obstet Gynecol. 2006;107(6):1399-410. https://doi.org/10.1097/01. AOG.0000220516.34053.48

10. Giornelli GH. Management of relapsed ovarian cancer: a review. Springerplus. 2016;5(1):1197. https://doi.org/10.1186/s40064-016-2660-0.

11. Chien J, Kuang R, Landen C, Shridhar V. Platinum-sensitive recurrence in ovarian cancer: the role of tumor microenvironment. Front Oncol. 2013;3: 251. https://doi.org/10.3389/fonc.2013.00251.

12. Luvero D, Milani A, Ledermann JA. Treatment options in recurrent ovarian cancer: latest evidence and clinical potential. Ther Adv Med Oncol. 2014; 6(5):229-39. https://doi.org/10.1177/1758834014544121.

13. Herzog TJ. The current treatment of recurrent ovarian cancer. Curr Oncol Rep. 2006 Dec 1;8(6):448-54. https://doi.org/10.1007/s11912-006-0074-9.

14. Cortez AJ, Tudrej P, Kujawa KA, Lisowska KM. Advances in ovarian cancer therapy. Cancer Chemother Pharmacol. 2018;81(1):17-38. https://doi.org/10. 1007/s00280-017-3501-8

15. Fields EC, McGuire WP, Lin L, Temkin SM. Radiation treatment in women with ovarian cancer: past, present, and future. Front Oncol. 2017;7:177. https://doi.org/10.3389/fonc.2017.00177.

16. Rai B, Bansal A, Patel FD, Sharma SC. Radiotherapy for ovarian cancersredefining the role. Asian Pac J Cancer Prev. 2014;15(12):4759-63. https:// doi.org/10.7314/apjcp.2014.15.12.4759.

17. Dembo AJ. Epithelial ovarian cancer: the role of radiotherapy. Int J Rad Oncol Biol Phys. 1992;22(5):835-45. https://doi.org/10.1016/03603016(92)90777-f.

18. Brown AP, Jhingran A, Klopp AH, Schmeler KM, Ramirez PT, Eifel PJ. Involved-field radiation therapy for locoregionally recurrent ovarian cancer. Gynecol Oncol. 2013;130(2):300-5. https://doi.org/10.1016/j. ygyno.2013.04.469. 
19. Lee SW, Park SM, Kim YM, Kim YS, Choi EK, Kim DY, Kim JH, Nam JH, Kim YT. Radiation therapy is a treatment to be considered for recurrent epithelial ovarian cancer after chemotherapy. Tumori J. 2011;97(5):590-5. https://doi. org/10.1700/989.10717.

20. De Felice F, Marchetti C, Di Mino A, Palaia I, Benevento I, Musella A, Musio D, Tombolini V. Recurrent ovarian cancer: the role of radiation therapy. Int J Gynecol Cancer. 2017;27(4):690-5. https://doi.org/10.1097/IGC 0000000000000958.

21. Del Carmen MG, Birrer M, Schorge JO. Clear cell carcinoma of the ovary: a review of the literature. Gynecol Oncol. 2012;126(3):481-90. https://doi.org/ 10.1016/j.ygyno.2012.04.021.

22. Cohen LE. Cancer treatment and the ovary: the effects of chemotherapy and radiation. Ann N Y Acad Sci. 2008;1135(1):123-5. https://doi.org/10. 1196/annals.1429.023.

23. Alongi F, Arcangeli S, Filippi AR, Ricardi U, Scorsetti M. Review and uses of stereotactic body radiation therapy for oligometastases. Oncologist. 2012; 17(8):1100. https://doi.org/10.1634/theoncologist.2012-0092.

24. Takeda A, Sanuki N, Kunieda E. Role of stereotactic body radiotherapy for oligometastasis from colorectal cancer. World J Gastroenterol: WJG. 2014; 20(15):4220. https://doi.org/10.3748/wjg.v20.i15.4220.

25. Kang JK, Kim MS, Kim JH, Yoo SY, Cho CK, Yang KM, Yoo HJ, Seo YS, Lee $\mathrm{DH}$, Kang HJ, Kim YH. Oligometastases confined one organ from colorectal cancer treated by SBRT. Clin Exp Metastasis. 2010;27(4):273-8. https://doi. org/10.1007/s10585-010-9325-0.

26. Habl G, Straube C, Schiller K, Duma MN, Oechsner M, Kessel KA, Eiber M Schwaiger M, Kübler H, Gschwend JE, Combs SE. Oligometastases from prostate cancer: local treatment with stereotactic body radiotherapy (SBRT). BMC Cancer. 2017;17(1):361. https://doi.org/10.1186/s12885-017-3341-2.

27. Navarria P, Ascolese AM, Tomatis S, Cozzi L, De Rose F, Mancosu P, Alongi F, Clerici E, Lobefalo F, Tozzi A, Reggiori G. Stereotactic body radiotherapy (sbrt) in lung oligometastatic patients: role of local treatments. Radiat Oncol. 2014;9(1):91. https://doi.org/10.1186/1748-717X-9-91.

28. Holy R, Piroth M, Pinkawa M, Eble MJ. Stereotactic body radiation therapy (SBRT) for treatment of adrenal gland metastases from non-small cell lung cancer. Strahlenther Onkol. 2011;187(4):245. https://doi.org/10.1007/s00066011-2192-z.

29. Singh $D$, Chen $Y$, Hare MZ, Usuki KY, Zhang H, Lundquist T, Joyce $N$, Schell MC, Milano MT. Local control rates with five-fraction stereotactic body radiotherapy for oligometastatic cancer to the lung. J Thor Dis. 2014;6(4): 369. https://doi.org/10.3978/j.issn.2072-1439.2013.12.03.

30. Hong JC, Ayala-Peacock DN, Lee J, Blackstock AW, Okunieff P, Sung MW Weichselbaum RR, Kao J, Urbanic JJ, Milano MT, Chmura SJ. Classification for long-term survival in oligometastatic patients treated with ablative radiotherapy: a multi-institutional pooled analysis. PloS one. 2018;13(4). https://doi.org/10.1371/journal.pone.0195149.

31. Palma DA, Olson R, Harrow S, Gaede S, Louie AV, Haasbeek C, Mulroy L, Lock M, Rodrigues GB, Yaremko BP, Schellenberg D. Stereotactic ablative radiotherapy versus standard of care palliative treatment in patients with oligometastatic cancers (SABR-COMET): a randomised, phase 2, open-label trial. Lancet. 2019;393(10185):2051-8. https://doi.org/10.1016/S01406736(18)32487-5.

32. Kunos C, Brindle J, Waggoner S, Zanotti K, Resnick K, Fusco N, Adams R, Debernardo $\mathrm{R}$. Phase II clinical trial of robotic stereotactic body radiosurgery for metastatic gynecologic malignancies. Front Oncol. 2012;2:181. https:// doi.org/10.3389/fonc.2012.00181.

33. Matsushita H, Jingu K, Umezawa R, Yamamoto T, Ishikawa Y, Takahashi N, Katagiri Y, Kadoya N. Stereotactic radiotherapy for Oligometastases in lymph nodes_a review. Technol Cancer Res Treat. 2018;17:1533033818803597. https://doi.org/10.1177/1533033818803597.

34. Macchia G, Lazzari R, Colombo N, Laliscia C, Capelli G, D'Agostino GR, Deodato F, Maranzano E, Ippolito E, Ronchi S, Paiar F. A large, multicenter, retrospective study on efficacy and safety of stereotactic body radiotherapy (SBRT) in Oligometastatic ovarian Cancer (MITO RT1 study): a collaboration of MITO, AIRO GYN, and MaNGO groups. Oncologist. 2020 Feb;25(2):e311. https://doi.org/10.1634/theoncologist.2019-0309.

35. Lazzari R, Ronchi S, Gandini S, Surgo A, Volpe S, Piperno G, Comi S, Pansini F, Fodor C, Orecchia R, Tomao F. Stereotactic body radiation therapy for oligometastatic ovarian cancer: a step toward a drug holiday. Int J Rad Oncol Biol Phys. 2018;101(3):650-60. https://doi.org/10.1016/j.jirobp.2018.03.058.

36. Iftode C, D'Agostino GR, Tozzi A, Comito T, Franzese C, De Rose F, Franceschini D, Di Brina L, Tomatis S, Scorsetti M. Stereotactic body radiation therapy in oligometastatic ovarian cancer: a promising therapeutic approach. Int J Gynecologic Cancer. 2018;28(8):1507-13. https://doi.org/10. 1097/IGC.0000000000001324.

37. Trippa F, Casale M, Draghini L, Anselmo P, Arcidiacono F, Maranzano E. Stereotactic body radiotherapy for lymph node relapse in ovarian cancer. Clin Oncol. 2016;1:1038.

38. Mazzola R, Fiorentino A, Ricchetti F, Giaj Levra N, Fersino S, Di Paola G, Lo Casto A, Ruggieri R, Alongi F. Cone-beam computed tomography in lung stereotactic ablative radiation therapy: predictive parameters of early response. Br J Radiol. 2016;89(1064):20160146. https://doi.org/10.1259/bjr. 20160146.

39. Mazzola R, Fiorentino A, Di Paola G, Levra NG, Ricchetti F, Fersino S, Tebano U, Pasetto S, Ruggieri R, Salgarello M, Alongi F. Stereotactic ablative radiation therapy for lung oligometastases: predictive parameters of early response by 18FDG-PET/CT. J Thorac Oncol. 2017;12(3):547-55. https://doi. org/10.1016/j.jtho.2016.11.2234.

40. Navarria P, De Rose F, Ascolese AM. SBRT for lung oligometastases: who is the perfect candidate? Rep Pract Oncol Radiother. 2015;20(6):446-53. https://doi.org/10.1016/j.rpor.2014.11.005.

41. Ohri N, Tomé WA, Romero AM, Miften M, Ten Haken RK, Dawson LA, Grimm J, Yorke E, Jackson A. Local control after stereotactic body radiation therapy for liver tumors. Int J Rad Oncol Biol Phys. 2018. https://doi.org/10.1016/j. ijrobp.2017.12.288.

42. Tagliaferri L, Budrukkar A, Lenkowicz J, Cambeiro M, Bussu F, Guinot JL, Hildebrandt G, Johansson B, Meyer JE, Niehoff P, Rovirosa A. ENT COBRA ONTOLOGY: the covariates classification system proposed by the Head \& Neck and skin GEC-ESTRO working group for interdisciplinary standardized data collection in head and neck patient cohorts treated with interventional radiotherapy (brachytherapy). J Contemp Brachyther. 2018;10(3):260. https:// doi.org/10.5114/jcb.2018.76982.

43. Lee CK, Asher R, Friedlander M, Gebski V, Gonzalez-Martin A, Lortholary A, Lesoin A, Kurzeder C, Largillier R, Hilpert F, Hardy-Bessard AC. Development and validation of a prognostic nomogram for overall survival in patients with platinum-resistant ovarian cancer treated with chemotherapy. Eur J Cancer. 2019;117:99-106. https://doi.org/10.1016/j.ejca.2019.05.029.

\section{Publisher's Note}

Springer Nature remains neutral with regard to jurisdictional claims in published maps and institutional affiliations.
Ready to submit your research? Choose BMC and benefit from:

- fast, convenient online submission

- thorough peer review by experienced researchers in your field

- rapid publication on acceptance

- support for research data, including large and complex data types

- gold Open Access which fosters wider collaboration and increased citations

- maximum visibility for your research: over $100 \mathrm{M}$ website views per year

At BMC, research is always in progress.

Learn more biomedcentral.com/submissions 